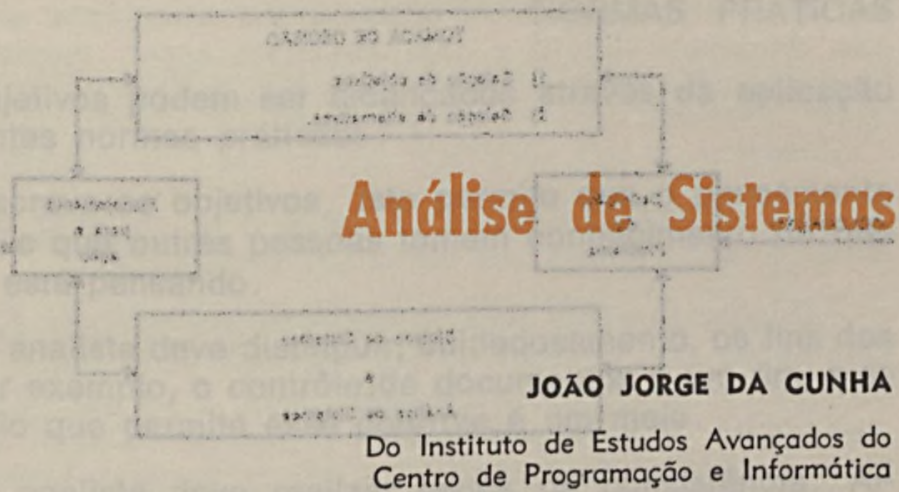

1. Introdução. -2 . Normas práticas. - 3. Fluxogramas. 4. Gabaritos de fluxogramas. -5 . Roteiro. -6 . Anexos: $1-$ Diagrama de blocos representativos de um projeto de sistema (Federação Nacional dos Bancos). II - Fluxograma de sistema. III - Fluxograma de processamento. IV - Fluxograma de programa. $\checkmark$ - Programa gerador de relatórios elaborado por alüno do Curso de Análise do Instituto de Estudos Avançados. VI - Definiçóes e conceitos.

\title{
INTRODUÇÃO
}

Chama-se análise de sistemas à metodologia científica que permite o exame racional de estruturas informáticas; objetivando o aperfeiçoamento de seu desempenho.

A preocupação do homem com o tempo e com o conhecimento (informação) foi sempre dominante. Enquanto, porém, - conhecimento aumentou de modo a se ter ameaça de um estado entrópico, o tempo continua do mesmo tamanho. Dai a construção das máquinas ou sistemas que, pela rapidez de reação aos estímulos originados do homem e pela capacidade pràticamente ilimitada de armazenar informações, possibilitaram o aproveitamento dêsse imenso esfôrço intelectual no tempo disponivel e invariável.

A análise dêsses sistemas informáticos é feita em várias etapas; conforme aparece na figura 1 , as setas indicando 0 processo interativo da análise. 


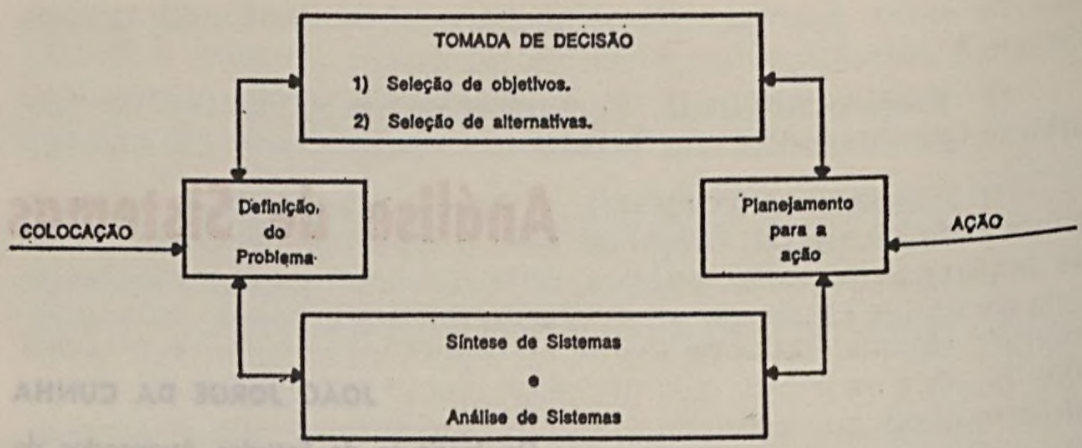

Flgure 1 - Processos do Análies de Slstemas

Dois dos cinco elementos da figura serão discutidos resumidamente: definição do problema e seleção de objetivos.

A definição do problema é um ponto crítico. Um entendimento vago da situação impede uma análise objetiva. Freqüentemente, o que parece ser um problema é realmente um sintoma de algum problema menos óbvio.

A importância da seleção de objetivos pode não ser evidente por si mesma. Há dois diferentes tipos de objetivos: 0 relacionado com $n$ sistema físico e o relacionado com os custos, a qualidade e a velocidade de operação.

A compatibilidade com outros sistemas, sua adaptabilidade para futuras exigências, a extensão do tempo na qual o sistema deve ser usado, estão incluídos no segundo tipo de objetivos e devem ser estabelecidos antes que os parâmetros do sistema físico sejam determinados.

O objetivo fundamental da análise é a implantação de um nôvo sistema, cabendo ao analista argumentar que, entre outras vantagens menores, o nôvo sistema:

a) possibilitará diminuição de custos;

b) aumentará a produtividade;

c) será mais eficiente.

Em atendimento aos objetivos o analista deverá se preocupar, no projeto do nôvo sistema, com os cinco Ms: Mão-deobra, Máquinas, Materiais, Moeda, Métodos. 


\section{NORMAS PRATICAS}

Os objetivos podem ser alcançados através da aplicação das seguintes normas práticas:

1) Escreva os objetivos. Isto permite que o pensamento fique claro e que outras pessoas tomem conhecimento do que 0 analista está pensando.

2) $\mathrm{O}$ analista deve distinguir, cuidadosamento, os fins dos meios. Por exemplo, o contrôle de documentos é um fim, mas o formulário que permite êsse contrôle é um meio.

3) O analista deve realizar testes de consistência. Alguns dos objetivos selecionados deverão ser modificados por falta de consistência. Por exemplo: diminuição de custos nos dois primeiros anos de funcionamento do nôvo sistema.

4) $O$ analista deve realizar vários testes para verificar se as idéias expostas estão completas. Por exemplo: mesa-redonda com os administradores do sistema.

5) $\mathrm{O}$ analista deve comprovar a viabilidade dos objetivos formulados. Será provável conseguir aquilo que se está objetivando? Os objetivos foram escalonados numa seqüência de Prioridades?

6) $O$ analista deve se prevenir contra incertezas. Deve usar um fator marginal nas suas estimativas. Por exemplo, se um dos objetivos é aumentar o volume de serviços, deve ser lembrado que a demanda tem um limite.

7) $\mathrm{O}$ analista deve distinguir as questões lógicas de questões de valor, isto é, deve estar certo de que conhece o que é possivel conhecer. Não deve usar dados imprecisos quando fôr possivel obter dados exatos.

8) $O$ analista deve objetivar ainda: (1) tornar fácil o acesso do usuário ao sistema; (2) tornar fácil o uso do sistema; (3) tornar fácil a operação do sistema; (4) estabelecer regime de Confiança entre o pessoal do sistema.

A seleção de objetivos é realmente fundamental em tôda análise. Se 0 analista seleciona os objetivos corretamente, mas não encontra as soluções corretas, certamente subotimizou sua Solução. E um êrro fàcilmente corrigivel, utilizando-se outra solução. 
Se, por outro lado, o analista não selecionou os objetivos que deveriam refletir o que desejaria fazer, resolveu o problema erradamente, apesar de ser boa a solução dada.

FLUXXOGRAMAS

Ao analisar o sistema existente e ao projetar o nôvo sistema, o analista precisa desenhar fluxogramas.

Os fluxogramas são representações simbólicas dos elementos de um processo e das relações entre êsses elementos arrumados de uma forma padronizada, a fim de facilitar a comunicação. Sua função é expor o padrão do fluxo de trabalho ou o processo de maneira tal que o usuário pode perceber ràpidamente todo 0 processo.

Adotando a terminologia da semiótica, diríamos que fluxograma é ửa linguagem analógica de caráter icônico.

Os fluxogramas têm muitas vantagens, sendo que a mais importante é a simplicidade, quando comparados com uma narrativa do mesmo processo. Numa narrativa os tópicos são tratados um de cada vez. E muito confuso tentar descrever em forma narrativa diferentes ações ocorrendo simultâneamente. Com um fluxograma, pelo contrário, pode-se indicar os acontecimentos paralelos sem dificuldade. O usuário pode dedicar sua atenção a um detalhe do diagrama, sem ser distraído por descrições não pertinentes.

Algumas normas práticas são apresentadas a seguir para desenhar fluxogramas de sistemas: comece com um sistema esquemático, contendo poucos detalhes; detalhe os processos complexos; examine as entradas de modo a estar certo de que compreendeu as diferentes peças de entrada existentes; analise, a seguir, as saídas e esteja certo de que as entendeu e que são aquelas quue você deseja que o sistema de fato pros duza. Esquematize as entradas e saidas para determinar os fluxos de cada uma. Você pode seguir as entradas através dos processos numa direção ou traçar as saídas em direção contrária. A maioria das análises envolve uma combinaçấo de ambos os procedimentos. Em cada caso, entretanto, você deve terminar com uma compreensão do fluxo dêsses elementos no sistema. Em geral, é preferível seguir cada espécie de entrada através de suas terminações e então seguir outra $\theta$ assim por diante, até que você possa combiná-las tôdas no diagrama. 0 conhecimento dos gabaritos de fluxogramas apresentados a seguir é indispensável nos trabalhos de análise de sistemas. 


\section{GABARITOS DE FLUXOGRAMAS:}

Hả 4 diferentes tipós de símbolos usados em fluxogramas:

a) símbolos gerais, que podem ser usados para descrever, vírtualmente, qualquer sistema, esteja ou não relacionado com o computador.

\section{a.1 - Processamento}

Um grupo de instrução que anunciam uma função de processamento de programa.

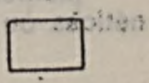

\section{a.2 - Entrada/Saida}

Qualquer função de um dispositivo de entrada/saida (fornecendo informaçőes para processamento, gravação, posicionamento da fita, etc.).

\section{a.3 - Linhas de fluxo}

Indicam os sentidos dos fluxos.

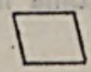

\section{a. 4 - Decisão}

Simbolo utilizado para indicar a possibilidade de desvios para diversos outros pontos do programa, de acôrdo com situações variáveis.

\section{a. 5 - Anotação}

Inclusão de uma aplicação adicional.

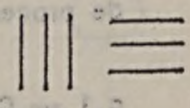

b) simbolos específicos.

\section{b. 1 - Documento}

Documentos e relatórios de tôdas as variedades.

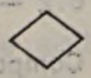

$$
\text { adicional. }
$$




\section{b.3 - Arranjo seqülencial, Intercalaçăo}

Uma operação em processamento de classificaçăo ou intercalaçăo.

\section{b. 4 - Memória fora de linha}

Memória fora de linha, em fichas, cartões, fitas magnéticas ou perfuradas.

\section{b.5 - Fita transmissora}

Uma fita de máquina de somar ou de prova.

Observação: Os símbolos descritos até agora năo têm, necessàriamente, relacionamento com o processamento de dados ou computadores. 0 grupo de símbolos descritos a seguir, entretanto, pertencem às operaçōes de processamento de dados.

\section{c.1 - Cartão perfurado}

Tôdas as variedades de cartăo perfurado.

\section{c.2 - Fita magnética}

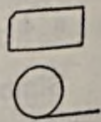

Componente de armazenamento de dados.

c.3 - Acesso aleatório de disco ou tambor

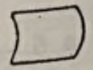

\section{c. 4 - Fita perfurada}

Fita de papel ou plástico.

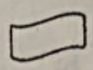

\section{c.5 - Teclado em linha}

Informação fornecida ou recebida de ou por um computador, utilizando um dispositivo.

\section{c.6 - Exibição}

Informaçŏes exibidas por dispositivos visuais.

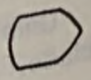




\section{c.7 -. Operaçăo manual}

Uma operação manual fora de linha, sem intervençăo de dispositivos eletromecânicos.

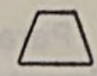

\section{c.8 - Operaçăo auxiliar}

Uma operação de máquina que suplementa a funçăo principal de processamento.

\section{c.9 - Modificação de programa}

Uma Instrução ou grupos de instruçǒes que modificam o programa.

\section{c.10 - Processo pré-definido}

do blocos.

Um grupo de operações năo incluidas no diagrama

\section{c.11 - Ligação de comunicaçōes}

Uma transmissăo automática de informação, entre locais diferentes, através de linhas de comunicaçăo.

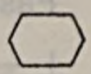

Além dos símbolos já descritos, há um pequeno grupo de símbolos que auxiliam a compreensão do diagrama, tanto para 0 autor como para Outras pessoas:

\section{d.1 - Conector (de operaçăo)}

Uma entrada ou uma saída de ou para uma outra parte do diagrama em blocos.

\section{d. 2 - Conector de página}

Uma conexão utilizada para indicar uma entrada ou saida de ou para outra página de diagrama.

\section{d. 3 - Direção de fluxos}

A direção do fluxo de dados ou de processamento.

\section{d. 4 - Terminal}
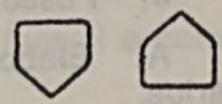

$\Delta \square$

$\nabla \bullet$ Programa.

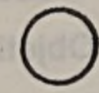

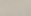
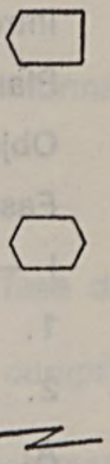
Para se realiżar uma análise de sistema é necessário, inicialmente, elaborar um roteiro padrão. Existem muitos dêsses roteiros e o que apresentamos a seguir é resultante de diversos seminários realizados pela Federação Nacional dos Bancos.

ROTEIRO PADRÃO

Introdução.

Planejamento de sistemas.

Objetivos do planejamento.

Fases principais do estágio de planejamento de sistemas:

I- A fase preparatória

1. Definição do projeto e autorização de estudo.

2. Organização do projeto: projeto.

A. Estruturação do comitê de assessoria e da equipe do

$\because 5$. B Método de trabalho da equipe do projeto.

C. Seminários técnicos de processamento de dados.

II - Fase de investigação inicial

1. Objetivos.

2. Introdução ao planejamento de sistemas.

3. Passos a serem seguidos durante a investigação inicial: nários.

A. Elaboração e distribuição de formulários e questio-

B. Orientação dos níveis gerenciais para que possam formular adequadamente suas necessidades e preencher os formulários próprios.

C. Desenvolvimento independente de novas idéias de sistemas pela equipe do projeto.

D. Consolidação e avaliação das informações obtidas. 
E. Seleção de áreas de aplicação para futuro desenvolvimento do sistema.

F. Estabelecimento inicial de prioridades.

III - Fase de estudos preliminares

1. Introdução.

2. Retrospecto.

3. Determinação dos limites do projeto.

A. Revisão e resumo das conclusões.

B. Identificação das áreas-problema.

f̧ão.

C. Estabelecimento dos requisitos básicos de informa-

4. Identificação preliminar dos benefícios.

5. Descrição dos objetivos.

6l. Elaboração de um plano de trabalho para a fase de planejamento detalhado de sistemas.

das. A. Identificação das tarefas individuais a serem cumpri-

B. Organização do trabalho de planejamento de sistemas. rem C. Identificação dos recursos humanos e materiais a sealocados.

jeto. D. Estruturação do esquema de desenvolvimento do pro-

E. Alocação de recursos humanos.

F. Definição de responsabilidades.

Gamentários. Determinação dos custos estimados e dos ajustes orPosição Revisão final dos resultados obtidos na fase II e comde um resumo de nível gerencial.

IV - Fase de planejamento detalhado de sistemas.

1. Introdução e objetivos.

2. Levantamento dos sistemas vigentes.

3. Construção da arquitetura dos sistemas substitutivos
Propostos. Postos. Especificação geral dos programas dos sistemas pro- 

dado.

5. Definição da configuração do equipamento recomen-

6. Processo de escolha do equipamento. mento.

A. Estabelecimento de critérios de avaliação de equipa-

B. Elaboração da documentação de sistemas.

C. Elaboração e expedição de cartas-convites aos fabricantes de equipamentos.

D. Avaliação das propostas apresentadas.

E. Elaboração e estudo de contrato com o fornecedor.

7. Definição dos recursos humanos, materiais e organizacionais disponiveis.

8. Estimativa de viabilidade econômica do projeto.

9. Estrutura final do esquema completo de desenvolvimento do projeto e estimativa de seus custos e orçamentos.

10. Revisão geral e preparo de um relatório conclusivo.

11. Apresentação e discussão final do projeto.

12. Encerramento dos trabalhos da equipe do projeto.

Dada a natureza introdutória dêste trabalho consideramos ANEXOS o interêsse na divulgação de alguns documentos que têm sido utilizados pelo Instituto de Estudos Avançados em seus cursos.

Os documentos que aparecem aqui sob o título de anexos são os seguintes:

I - Diagrama de blocos, representativo de um projeto de sistema (Federação Nacional dos Bancos).

II - Fluxograma de sistema.

III - Fluxograma de processamento.

IV - Fluxograma de programa.

V - Programa gerador de relatórios, elaborado por aluno do Curso de Análise do Instituto de Estudos Avançados.

$\mathrm{VI}$ - Definições e conceitos. 
DIAGRAMA DE BLOCOS REPRESENTATIVO DO PROJETO

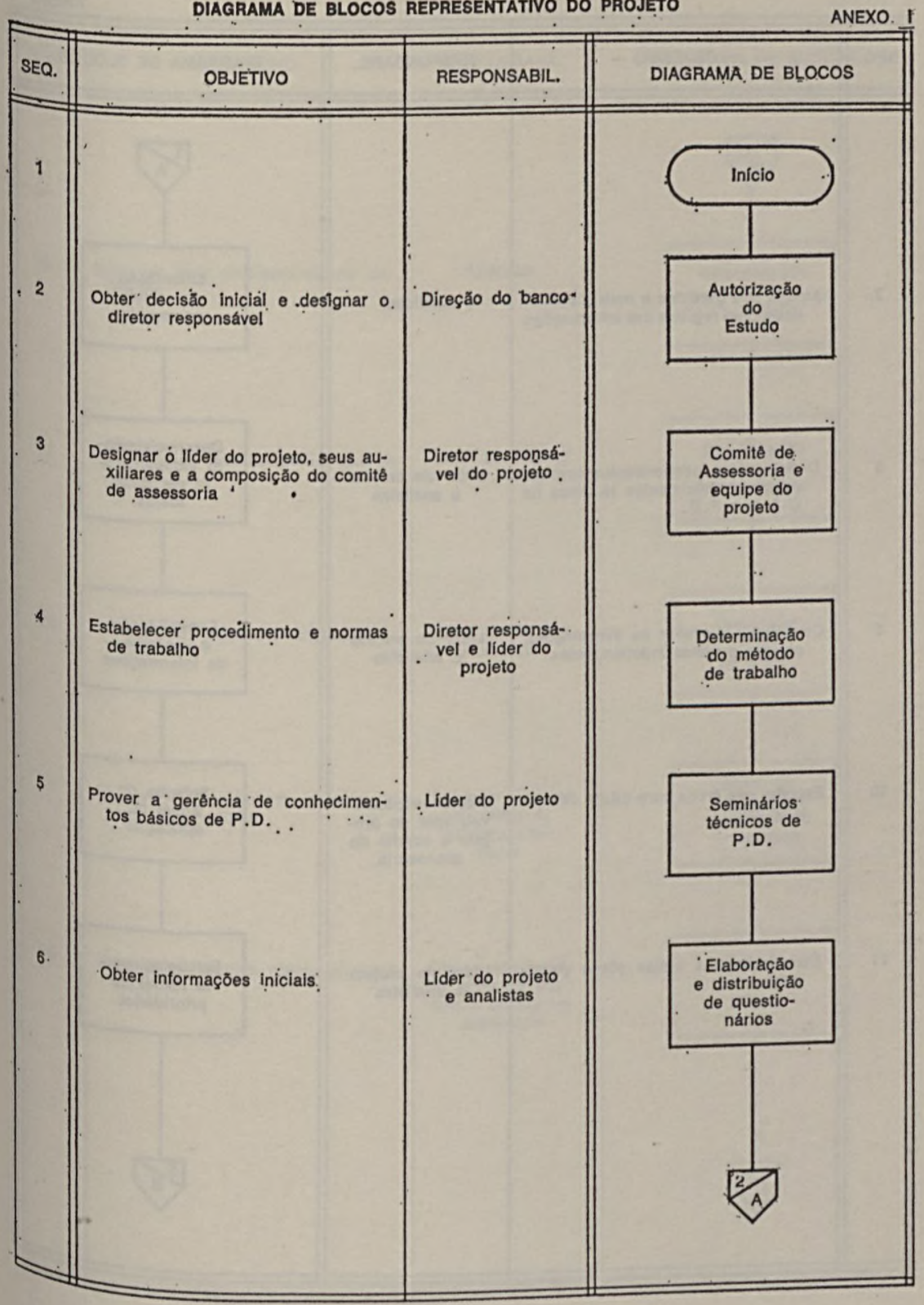


Auxilio aos gerentes $\theta$ mais sistematizaçăo no registro das informaçōes

Definir idéias independentes com base em conhecimentos técnicos de $O \& M$ \& P.D.

Escolha das áreas para futuro desenvolvimento

Fixar primeiras idélas sôbre prioridades
RESPONSABIL:

DIAGRAMA DE BLOCOS

Lider do projeto

e analistas

Líder do projeto

$\theta$ analistas

Diretor responsável, líder do projeto e comitê de assessoria

Líder do piojeto e analistas

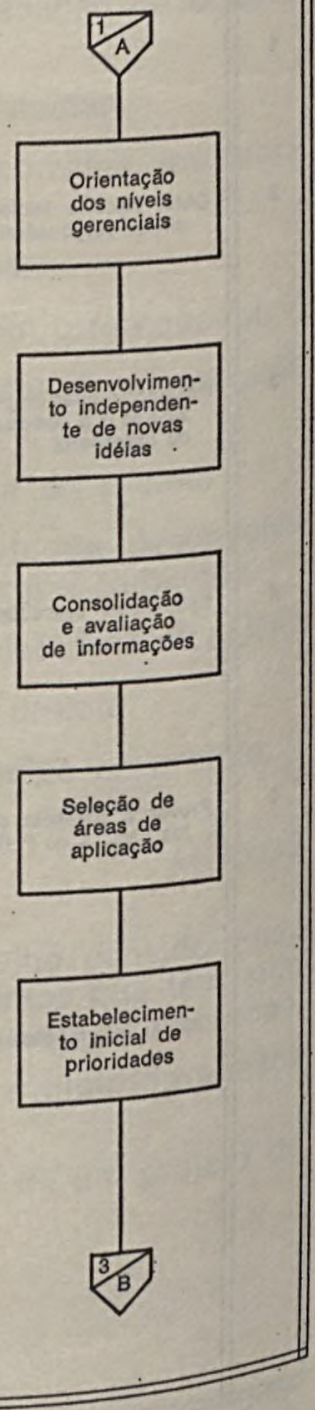




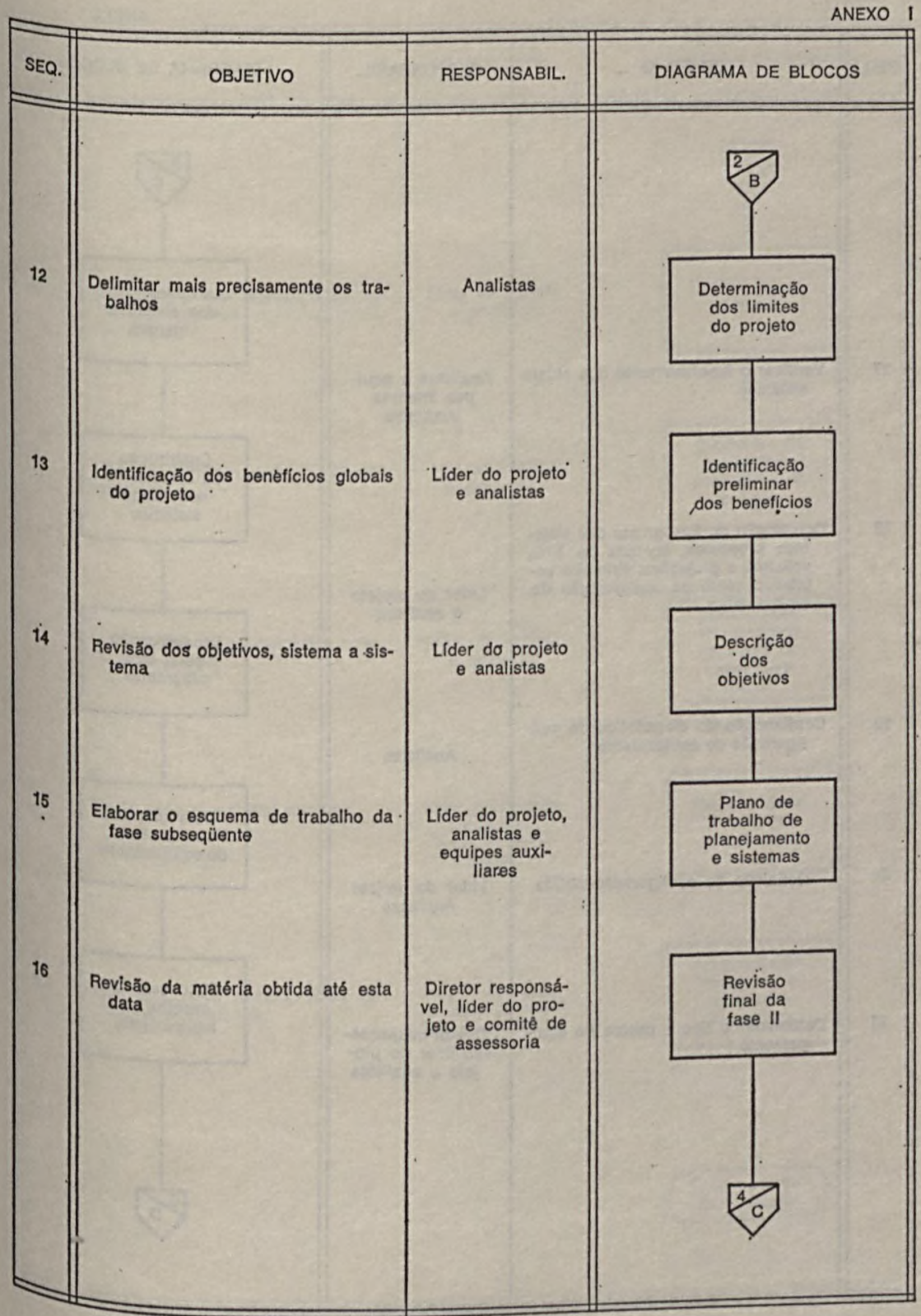




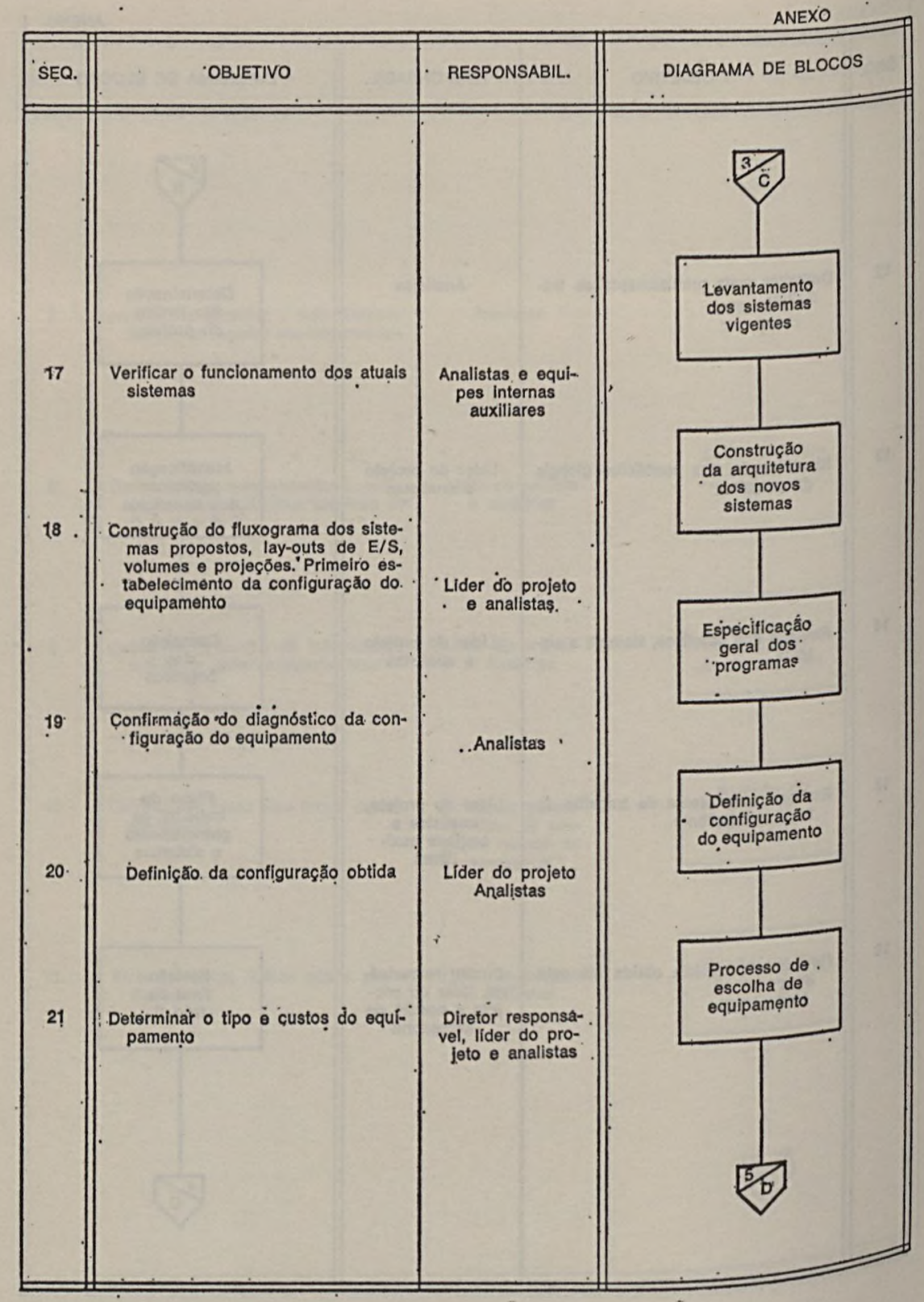




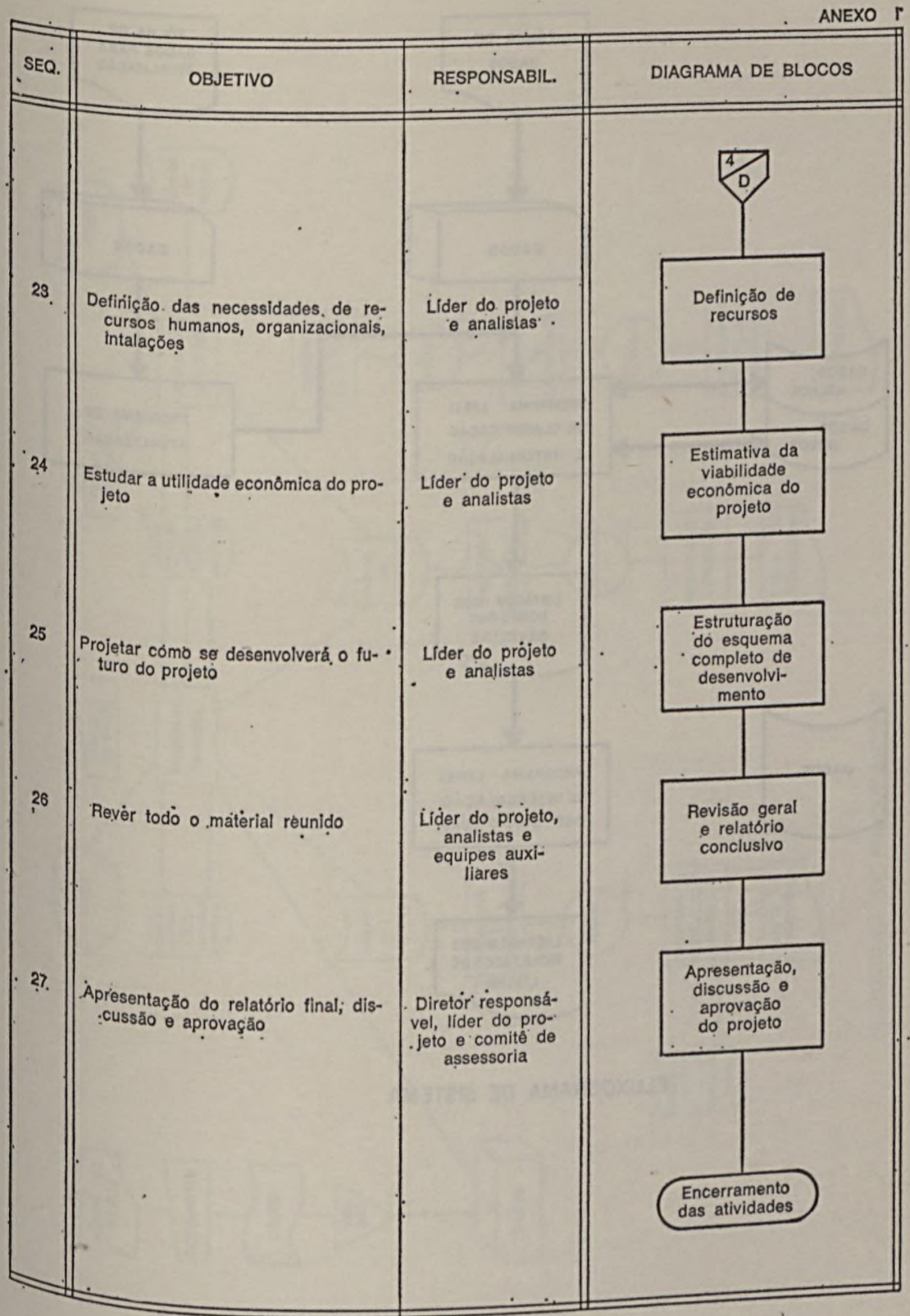




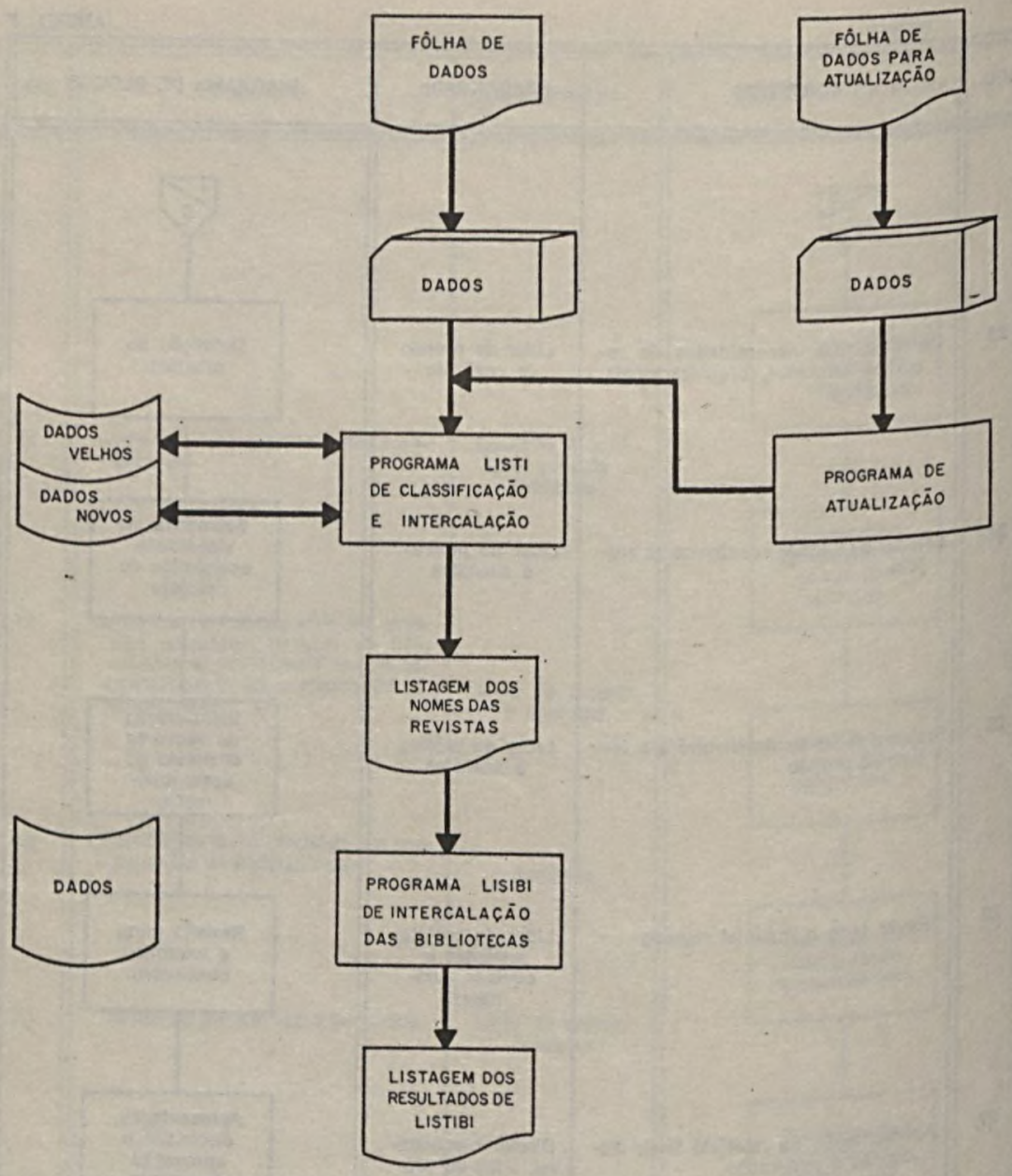

FLUXOGRAMA DE SISTEMA 


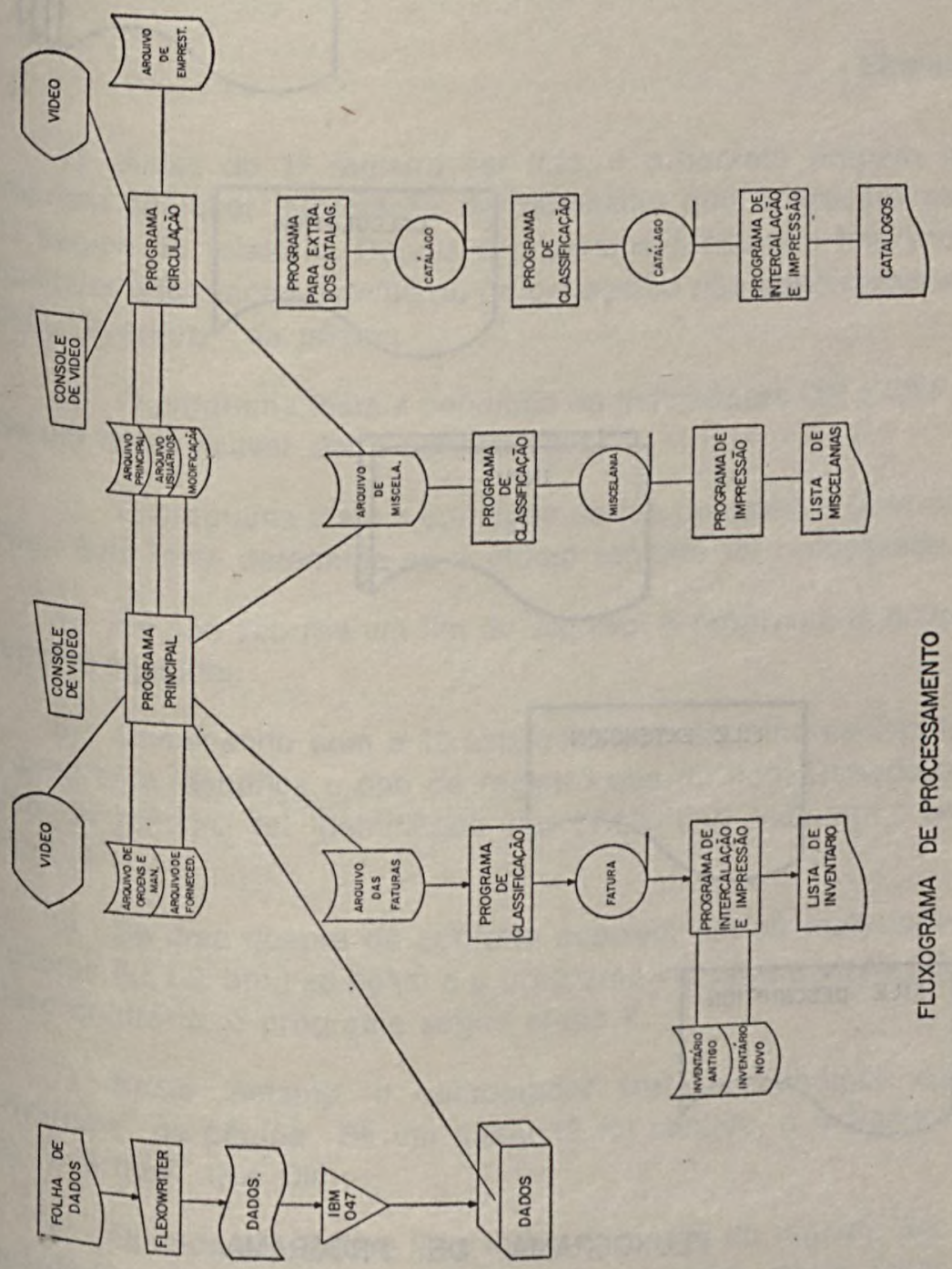



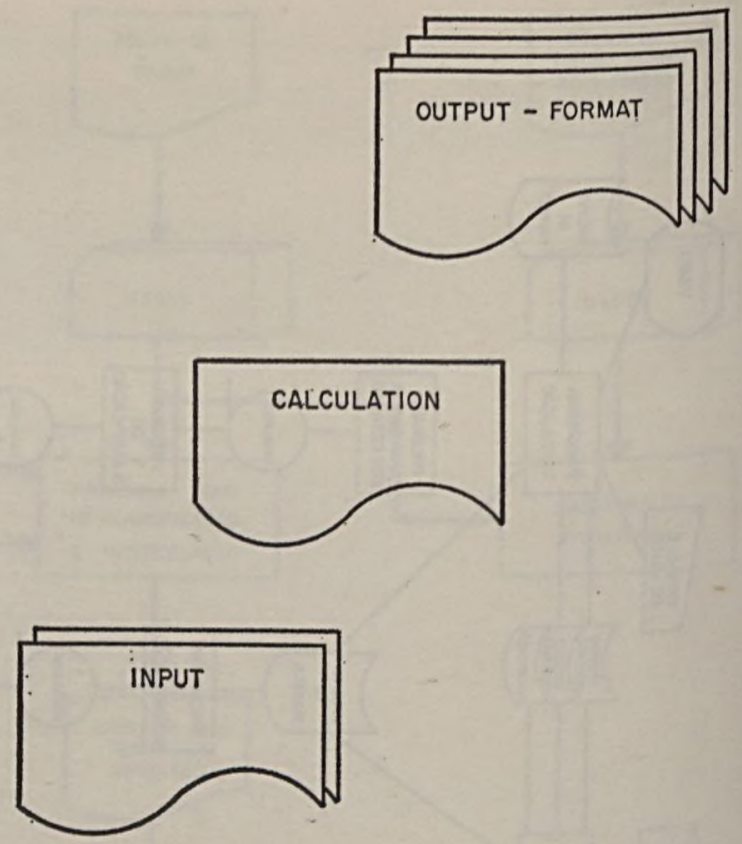

FILE EXTENSION

FILE DESCRIPTION

FLUUXOGRAMA DE PROGRAMA 
ANEXO IV

\section{FLUXOGRAMA DE PROGRAMA}

Etapas

1) Antes do 19 registro ser lido, o programa prepara $e$ imprime qualquer informação de cabeçalho que aparecerá na 1a página do relatório. Depois o programa prepara e imprime qualquer informação-detalhe ou de cabeçalho não condicionada pelo "overflow" de página.

2) O programa testa a condição de indicadores ON e OFF. Se um dêles estiver $\mathrm{ON}$ o serviço pára.

3) O programa testa a condição de fim de arquivo (End of File). Este teste determina se o último registro foi processado.

4) Se não ocorreu um fim de arquivo, o programa lê nôvo registro seguinte.

5) Começando com a 1 ạ especificação da fôlha de Input, o programa identifica o tipo de registro que foi lido. Quando o tipo de registro foi identificado um "Resulting Indicator" se liga ON.

6) Se uma quebra de contrôle ocorreu, um ou mais indicadores (LI, L2, etc.) se ligam e o programa vai para a etapa 10. Caso contrário, o programa segue etapa 7 .

7) Neste instante, o computador testa a condição de "overflow" de página. Se um canal 12 foi sentido, o indicador de "overflow" fica ON.

8) Quando um dado é lido, todos os dados do registro são guardados temporàriamente. Agora o programa move êstes Campos de dados especificados na fôlha "Input" para uma diferente área de memória. Esta nova área guarda sòmente os dados que serão usados depois para cálculos de saída. 
9) Se cálculos em tempo de detalhe foram especificados, êles são feitos. Êsses cálculos são feitos na ordem em que foram apresentados nas especificações. Após os cálculos terem sido computados, o programa processa registros-detalhe e cabeçalho. O programa continua a processar registros-detalhe, um de cada vez, até que todos os registros tenham sido lidos ou uma quebra de contrôle ocorra.

10) Se ocorre uma quebra de contrôle, os cálculos em tempo de total são feitos.

11) Após os cálculos terem sido feitos, o programa faz com que tôdas as linhas de total para aquêle indicador de nivel de contrôle que estiver ON sejam impressas ou perfuradas.

12) Se o indicador de último registro estiver OFF, o programa deve testar "overflow" de página (etapa 7). Se o indicador de último registro estiver $\mathrm{ON}$, o computador deve parar.

As conclusões a serem tiradas do fluxograma são as seguintes:

a) Os cálculos são feitos antes das linhas de saída serem produzidas.

b) Os dados de um registro que motivaram uma quebra de contrôle não são usados até que totais para o grupo anterior sejam computados e produzidos como saída.

c) Um indicador de parada, se estiver ON, pára o computador após todo o processamento de complementação daquele registro. 


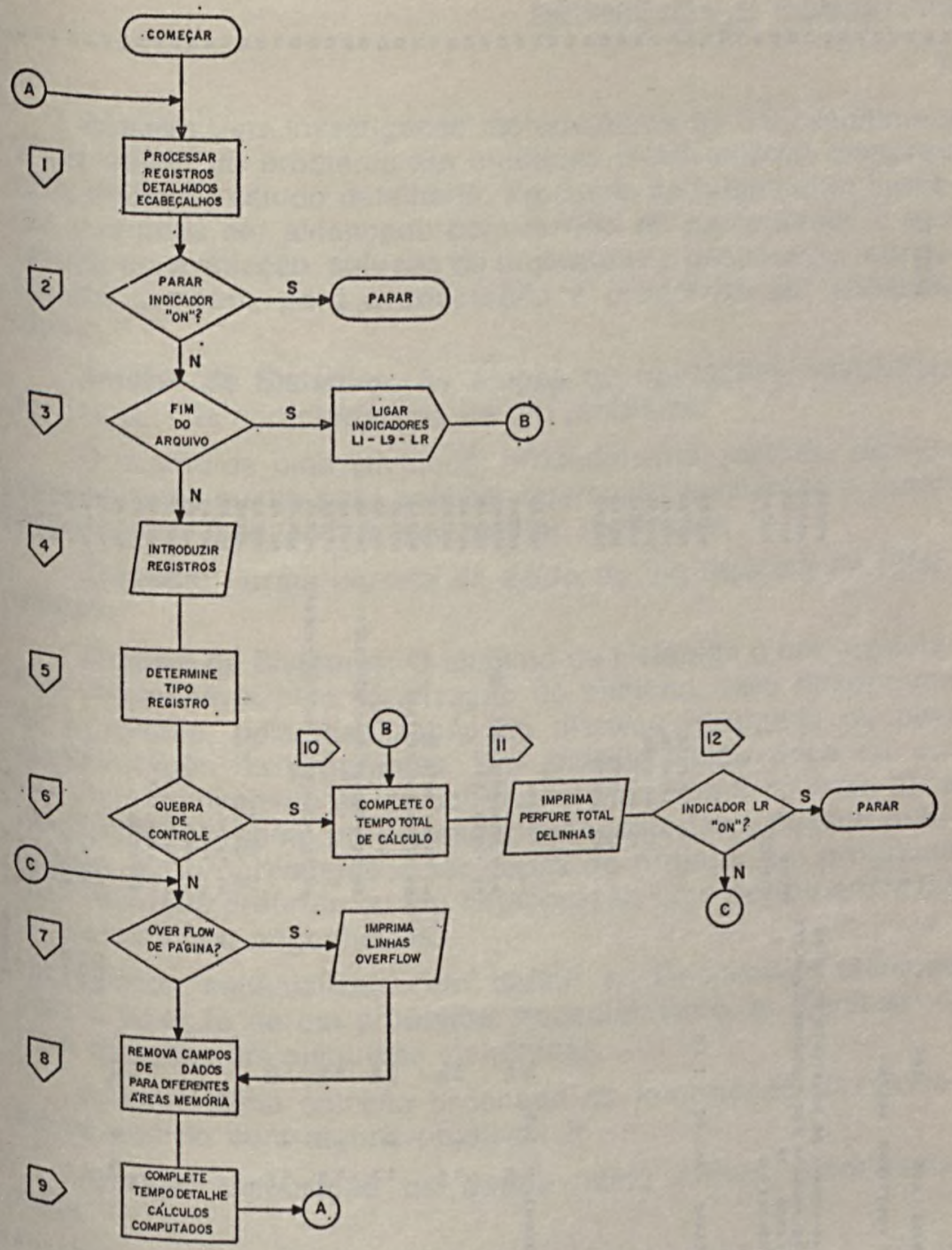

FLUXOGRAMA DE PROGRAMA 
章

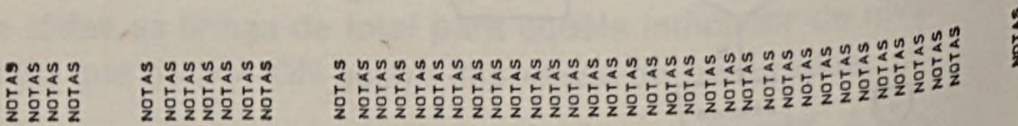

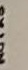
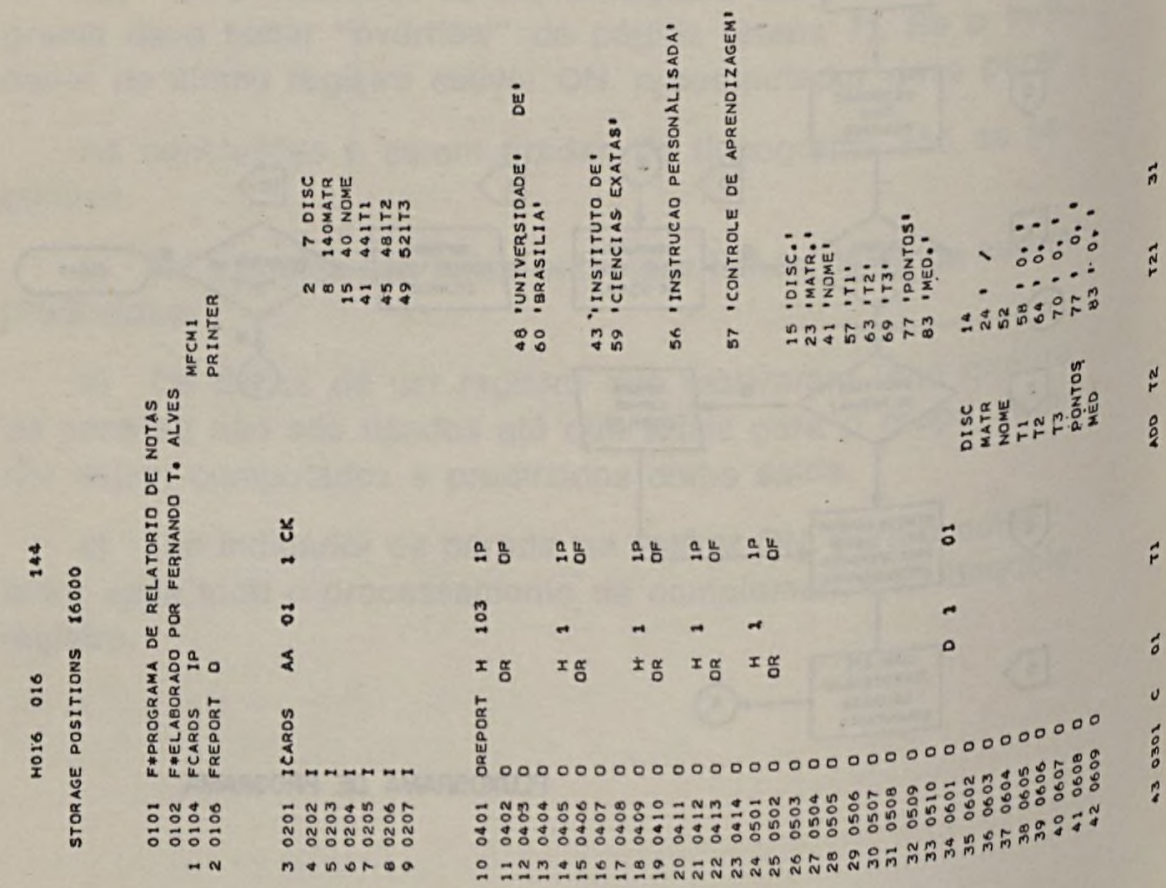

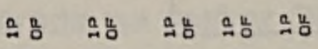

$\overrightarrow{0}$

品 $\rightarrow+$ -

$x \frac{\alpha}{\alpha} \quad x \frac{\alpha}{\alpha} \quad \pm \frac{\alpha}{\alpha} x \frac{\alpha}{\alpha} \quad I \frac{\alpha}{\alpha}$

产

就 00000000000000000000000000000000

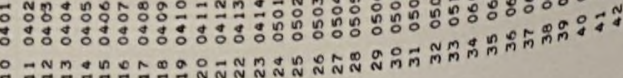




\section{DEFINIÇÕES E CONCEITOS}

Análise: Uma investigação metodológica de um problema e a separação do problema em unidades relativamente menores, para posterior estudo detalhado. Processo de julgamento humano, que pode ser alcançado com auxílio de computador e que resulta em avaliação, solução de problemas e descoberta, contribuindo, também, para a adaptação e progresso em sistemas objeto 17

Análise de Sistemas: As etapas ou operações envolvidas no estudo das caracteristicas de um problema.

O exame de uma atividade, procedimento, método, técnica ou empreendimento para analisar operações existentes e determinar como êles podem ser melhor realizados. ${ }^{7}$

Acurada: Forma correta da saída de um sistema de informação. 7

Analista de Sistemas: $O$ analista de sistemas é um especialista responsável pela idealização do sistema, pelo fluxograma de programa, pela idealização do sistema avançado ou pela administração de programas. Um analista típico deve ter um Currículo equivalente ao de um engenheiro com 3 ou mais anos de experiência como programador avançado. Deve possuir habilidades em programação e ser capaz de projetar um programa com recursos próprios ou em colaboração com outros analistas de sistemas ou engenheiros.

Pessoa especializada em definir e desenvolver técnicas Para a solução de um problema. Especialmente as técnicas Para soluções em máquinas eletrônicas.

Arquivo: Uma coleção ordenada de informação direcionada de acôrdo com alguns objetivos. ${ }^{19}$

Arranjo: Disposição de dados numa ordem predeterminada. 7

nheciaixa preta: Um sistema cujos trabalhos atuais não são coatravés e cujo comportamento sòmente pode ser estudado, dos Canal: Um meio de comunicação para transmissão de da̧ão entre dois ou mais pontos. Também chamados linha, ligaou caminho. 
Comunicação: 0 fluxo da informação de um ponto (a orígem) a outro (o receptor). ${ }^{7}$

Compatibilidade: Característica de computadores pela qual um computador pode aceitar e processar dados por outro computador sem conversão ou modificação de código.

Compatibilidade: Significa a habilidade de expandir o sistema, sem ter que mudar as características das unidades individuais. ${ }^{20}$

Configuração: Um grupo de máquinas que são interconectadas e são programadas para funcionar como um sistema. ${ }^{7}$

Cibernética: Estudo da comunicação e contrôle em máquinas e organismos vivos. Teoria do contrôle e da comunicação na máquina e no animal. 28

Cultura cibernética: $E$ um sistema cibernético com regras internas, elementos humanos, o homem na curva de realização e valôres variáveis e competitivos. ${ }^{6}$

Distribuição do tempo (time-Sharing): Torna possível acesso direto simultâneo a um banco de dados. ${ }^{19}$

Um método de operação em que os serviços do computador são distribuídos por vários usuários para diferentes finalidades ao mesmo tempo, pelo menos aparentemente. Se bem que o computador seja utilizado para cada usuário em seqüência, a grande velocidade do computador faz com que se pense que os usuários estão todos usando-o simultâneamente.

Diferencial semântica: Uma escala de medição de atitudes.

Diagnóstico de Sistemas: Além de testar um componente individual, o diagnóstico de sistemas utiliza o sistema inteiro de modo semelhante ao seu curso operacional. Os programas assemelhando-se aos programas operacionais serão usados de preferência aos programas sistemáticos que exigem esquemas lógicos. Isto detectará, normalmente, falhas de funcionamento do sistema, mas não isolará os componentes das falhas. ${ }^{11}$

Documento: Qualquer instrumento contendo registro de dados, não importando sua forma física ou características. Informação grupada e registrada, capaz de ser manuseada e lida.

Documentação: A preparação, manuseio e distribuição de informação expressa fisicamente. 
Descritor: Uma palavra ou combinação de palavras usadas para descrever um conceito num documento ou outro material informativo.

Enderêço: Uma representação codificada dá destinação de dados ou de seu terminal de origem. Terminais múltiplos numa linha de comunicação, por exemplo, devem ter um único enderêço. 12

Estudos de Sistemas: O processo detalhado de determinar um sistema ou um conjunto de procedimentos para usar um computador para definir funções ou operações e estabelecer especificações a serem usadas para a seleção do equipamento adequado às necessidades especificas.

Eficiência da Informação: A relação da atual entropia negativa com a entropia máxima, usando o mesmo conjunto de signos. 21

Entropia: Uma mensagem de desordem ou de improbabilidade do próximo estado. A entropia tende sempre a crescer e é máxima onde a seqüência de eventos é completamente impredizível. 21

A informação não disponível num grupo de documentos. 0 grau de desorganização numa configuração informacional. ${ }^{19}$

A mensuração da desordem num sistema. Um sistema tende para o estabelecimento de uma distribuição uniforme de sua energia. Assim, no máximo de entropia tudo é uniforme e o sistema não contém informação. ${ }^{20}$

mi Medida da energia não disponível num sistema termodinâo fechado.

form teoria da informação, medida da quantiliade de inrmação numa mensagem.

ganenos precisamente, sinônimo da tendência para a desorganização e a desordem em qualquer sistema objeto. ${ }^{28}$

Possa Eficiência do Sistema: A probabilidade de que o sistema tessa alcançar com êxito uma demanda operacional num dado quando operado sob condições específicas. ${ }^{1}$

Se A eficiência do sistema (E) é uma medida da extensão que requide esperar de um sistema para alcançar um conjunto de dến ncia e capacidade do sistema. 
Fluxograma de Sistema: Representação gráfica do sistema no qual as informações fornecidas por um documento - fonte - são transformadas em documentos finais.

Fluxo de Informação: A rota da informação (documentos, dados, feed-back, estatísticas, etc.,) enquanto desempenha sua função de contrôle do ambiente manufaturado. ${ }^{30}$

indice: Uma lista de referência ordenada, relativa ao conteúdo de um arquivo ou documento, juntamente com chaves ou notações de referência para identificação ou localização daqueles conteúdos.

Informação: Dado registrado, classificado, organizado, relacionađo ou interpretado dentro de um contexto ajustável a um significado. cidas. ${ }^{2}$

O significado atribuido ao dado por convenções conhe-

Dado processado e avaliado, especialmente como derivado de uma coleção de documentos ou outros registros gráficos.

Conhecimento ou instrução adquiridos pelo receptor através de dado processado. ${ }^{7}$

Conhecimento de forma fatual, usualmente obtido de outros, ou de qualquer dos vários meios de armazenamento, tornado disponivel por comunicação ou uso. ${ }^{40}$

Logon: A unidade para expressar a quantidade de informação estrutural, diferente de METRON, a unidade para expressar a quantidade de informação métrica. ${ }^{21}$

Média: Veículo para comunicação de idéias. ${ }^{20}$

Medium: A substância física sôbre a qual os dados são registrados, tais como fita magnética, cartões perfurados, etc.

Mensagem: Conjunto de palavras, símbolos, impulsos elétricos ou furos, objetivando fornecer informação.

Modo de Apresentação: $O$ modo pelo qual uma informação de saída é apresentada para uso humano ou de máquina. 
Off-Line: Fora de circuito. Em telegrafia, fitas de papel freqüentemente são perfuradas "off line" e então transmitidas, usando o transmissor da fita de papel. 1112

On-Line: Diretamente no circuito. Em telegrafia, transmitir diretamente na linha antes que, por exemplo, seja perfurada a fita para transmissão posterior. ${ }^{11} 12$

Operação de equipamento de E/S sob o contrôle direto da UCP do computador. ?

Programadores: Êsses especialistas são responsáveis pela programação e codificação de fluxogramas. Um programador típico deve ter instrução equivalente ao 2 \% ciclo, com 1 ou mais anos de experiência em programação, tanto em linguagem cientifica como comercial.

Programadores avançados: São especialistas capazes de desenvolver programas avançados, nivelando-se aos analistas de sistemas, principiantes.

Projeto de Sistema: 0 projeto de alguma combinação homem-máquina, a fim de executar um conjunto de tarefas operacionais necessitadas.

Projetar (design): Organizar mentalmente. Conceber como um todo (um sistema). Inventar. O processo interativo para deotimizalver sistemas de engenharia desde que os recursos sejam otimizados de acôrdo com os objetivos desejados.

Relevância: (Precisão): A percentagem daqueles itens que dão recuperados e que são relevantes para o requisitante. Num dado sistema, relevância e repetição são inversamente propor-
Cionais. ${ }^{30}$

Ou Recuperação (Retrieval): A operação de recuperar energia ¿eleção objeto prèviamente estocado. Recuperação envolve 1 cação de um ou mais loci no qual há objetos usáveis: ${ }^{2}$ a apliestado de energia ao objeto ou objetos para determinar seu $e^{3}$ perceber a energia apresentada pelo objeto. ${ }^{21}$

do Real'mentação (feed-back): O reflexo de um sinal, indicanresultado da ação, de modo a determinar futuras ações. ${ }^{20}$ Reversão parcial dos efeitos de um dado processo às suas
Origens. 
A parte de um sistema de comunicação que vai do receptor à origem da mensagem .

Contrôle do sistema pela saída do sistema, isto é, um contrôle autocorrigivel ou autocompensável. ${ }^{7}$

Parte de uma volta do sistema que, automàticamente, traz de volta informação sôbre a condição sob contrôle. ${ }^{28}$

Informação obtida próximo ou no fim de um sistema que é, então, usada para modificar a entrada para o sistema, de modo então, usada para modificar a entrada para o sistema, deção de
a ajustar a quantidade, a qualidade, etc., da informaça. ${ }^{30}$

Sistema: Uma coleção ordenada de fatos relacionados por interação regular. Uma coleção organizada (de homens, máquinas, etc.) e os métodos requeridos para alcançar um objetivo específico. O exame de uma atividade considerando-se os processos, métodos e técnicas a serem utilizados nessa atividade. Para se determinar o que deve ser conseguido e como as operações necessárias podem ser realizadas.

Sistema adaptativo: Um sistema adaptativo continua a alcançar seus objetivos diante de um amb ente em mutação ou da deterioração na performance de alguns de seus elementos. ${ }^{6}$

Sistema complexo: E definido como um sistema composto de conjuntos de subsistemas interconectados. ${ }^{65}$

S'stema (outros conceitos): Um arranjo regular ou ordenado de componentes ou partes numa série ou todo conectado $e$ interrelacionado; uma série ou grupo de componentes necessários a alguma operação. ${ }^{21}$

Um agregado ou conjunto de objetos unidos de alguma forma de interdependência ou interação local; um grupo de diversas unidades combinadas natural ou artificialmente de modo a formar um todo integral e funcionar, operar ou mover-se em uníssono e, freqüentemente, em obediência a alguma forma de contrôle; um todo orgânico ou organizado; o universo, o sistema solar, o sistema nervoso.

Um sistema é uma coleção de elementos humanos e mecânicos integrados para alcançar um desejado objetivo comum pela manipulação e contrôle de materiais, informação, energia e pessoas.

E possível pensar em sistemas como caracterizados por seus objetivos ou por seus elementos ou pela sua mais avançada tecnologia. Assim, tem-se sistemas de comando e de con. Ascomecânicos. ${ }^{17}$ 
A combinação de dois ou mais subsistemas ou conjunto de equipamentos geralmente separados fisicamente quando em operação (p. ex., aviões com todos os seus subsistemas elétricos, eletrônicos, hidráulicos e pneumáticos). ${ }^{1}$

Sistema é uma coleção de diversos elementos em interação e que funcionam (comunicam-se com um ambiente específico para processar informação de modo a alcançar um ou mais objetivos desejados). A realimentação é essencial. Alguns de seus "inputs" podem ser estocásticos e uma parte de seu ambiente pode ser competitiva. ${ }^{6}$

Uma coleção de partes unidas de alguma forma de interação regulada, um todo organizado. ${ }^{19}$

Uma coleção de operações consecutivas e procedimentos requeridos para cumprir um objetivo específico numa atividade, organização ou ambiente.

Um conjunto de objetos unidos para formar uma unidade funcional. Qualquer conjunto de objetos ou eventos relacionados, inclusive a organização coletiva de informações que possuam; os meios de adquirir, armazenar, transmitir, controlar ou mesmo processar tais informações; tudo em relação, mas distinto do ambiente externo no qual o comportamento e a história do sistema-objeto são envolvidos.

Sintese de Sistemas: O planejamento de procedimentos para resolver um problema. Isso pode envolver, entre outras coisas, a análise do problema, a preparação do fluxograma, o detalhamento, a experimentação, o desenvolvimento de sub-rotinas, a alocação de espaços de armazenagem, a especificação te gráficos de entrada e saída e a incorporação de um computador nôvo num sistema de processamento de dados completo.

\section{Salários:}

Seguin salários nos Sistemas de Informação dos EUA são os

\section{a) Analistas:}

1. Especializado: US $\$ 300,00 /$ semana

2. Experimentado: US $\$ 200,00 /$ semana

3. Principiante: US $\$ 150,00 /$ semana

b) Programador:

1. Especializado: US $\$ 200,00 /$ semana

2. Experimentado: US $\$ 120,00 /$ semana

3. Principiante: US $\$ 95,00 /$ semana 
c) Programadores com responsabilidades gerenciais: US\$ $370,00 /$ semana

d) Operador:

1. Especializado: US $\$ 128,00 /$ semana

2. Principiante: US $\$ 88,00 /$ semana

3. Tabulador:

Supervisor: US $\$ 150,00 /$ semana

Supervisor-especializado: US $\$ 280,00 /$ semana

Principiante: US\$ $88,00 /$ semana

e) Perfurador:

1. Especializado: US $\$ 200,00$ /semana

2. Supervisor: US $\$ 123,00 /$ semana

3. Principiante: US $\$ 66,00 /$ semana

Transmissão: 0 movimento de dados de um ponto chamado origem para um ou mais pontos chamados receptores, tanto por meios físicos como elétricos. ${ }^{7}$

Tratamento do sistema: Uma metodologia de solução de problema que envolve uma análise do sistema atual e subseqüentemente, um projeto melhorado de um nôvo sistema. ${ }^{7}$

Terminal: Qualquer dispositivo capaz de enviar e/ou receber informação através de um canal de comunicação. Os meios pelos quais as decisões do sistema são comunicadas ao ambiente que é afetado pelo mesmo. Uma grande variedade de terminais tem sido construída, incluindo teleimpressoras, teclados especiais, dispositivos luminosos, tubos catódicos, unidades de radar, telefones, etc. ${ }^{11}$ e 12

Um ponto numa rêde de comunicação no qual os dados podem entrar ou sair.

Um dispositivo de E/S destinado a receber ou enviar dados originais, como parte de um sistema de transmissão de dados. Equipamento destinado a pôr o usuário em comunicação com um computador. Usualmente afastado do compução com um computador. Usualmente afastado do compu-
tador, junto ao usuário; requer programa especial no compor
tador. ${ }_{30}$

Thesaurus: Um léxico onde as palavras são grupadas por idéias; um agrupamento ou classificação de sinônimos ou quaidéias; um agrupamento ou classificação de sinônimos ou
se sinônimos; um conjunto de equivalentes classes terminolo
gicas. ${ }^{10}$ 
Um conjunto de palavras definindo a linguagem do usuário de um sistema de informação, geralmente associado com uma lista de sinônimos, a lista de freqüência de palavras e um conjunto de regras associadas.

Utopia: é um sistema cujos elementos são humanos, inclusive no processo de realimentação. ${ }^{6}$

Viabilidade: Viabilidade é a probabilidade de que o sistema ou subsistemas operem da maneira desejada quando operado no ambiente encontrado. Viabilidade se relaciona com a performance do sistema. Se certas partes do sistema falham, a performance projetada não é obtida. A degradação pode ser parcial, quando, então, eventos de performances parciais são obtidos; quando a degradação é total, os eventos de performances são inteiramente insatisfatórios, a menos que correções de falhas sejam aplicadas. A viabilidade é, também, relacionada com o custo: com performances reduzidas, devido à baixa viabilidade, há necessidade de se adicionar fatôres de custo. ${ }^{23}$

Viabilidade (probabilidade) e possibilidade são conceitos que se confundem, mas, viabilidade é definida como a probabilidade de que um sistema se comporte como esperado para a duração da missão, dado que o sistema esteja, inicialmente, no estado de partida. Para um sistema com ciclos já realizados, no qual a média de tempo ocioso é muito menor do que a média do tempo de uso, a média de tempo de reparo deve ser tomada muito abaixo da média de tempo ocioso ou os reparos não poderão ser feitos sem significativamente decrescer a viabilidade do sistema. ${ }^{33}$

A viabilidade é a probabilidade de um dispositivo realizar suas finalidades adequadamente pelo período de tempo requerido, sob as condições de operação encontradas. Portanto, a viabilidade pode ser definida como a medida da atuação de sistemas com êxito. ${ }^{18}$

BIBLIOGRAFIA INDICADA NAS DEFINIÇŌES E CONCEITOS:

Practic BLANCHARD, B.S. and Lowery, E.E. Maitainability - Principles and ractices., McGraw-Hill, New York, 1969, 336p. ${ }^{2}$. BLUMENTHAL, S.C., Management Information Systems - A Frame-
$392 \mathrm{p}$. 

1967.

3. CHESTNUT, H. - Systems Engineering Methods. Wiley, New York,

4. CLELAND, D.I. and King, W.R. - Systems Analysis and Project Management, McGraw-Hill, New York, 1968, 315p.

5. DEUTSCH, R. - System Analysis Techiniques, Prentice-Hall, Englewood Cliffs, 1969, 472p.

6. DEWAN, E.M., ed. Cybernetics and the Management of Large Systems, Proceedings of the 2nd Annual Symposium of the American Society for Cybernetics, Spartan, New York, 1969, 264p. Chapter by H. K. Hughes, Utopias and Cybernetic Cultures.

7. DIPPEL, G. and HOUSE, W.C., Information Systems - Data Processing and Evaluation. Scott - Foresman, Genview, Illinois, 1964, 493p.

8. EMERY, J.C. - Organization Planning and Control Systems Theory and Technology, MacMillan, Toronto, 1969, 166p.

9. GOLDMAN, A.S., and SLATTERY, T.B., Maintainability - A Maior Element of System Effectiveness, Wiley, New York, 1967, 282p.

10. MARTIN, J. - Design of Real-Time Computer Systems, PrenticeHall, Englewood Cliffs, 1967, 629p. Englewood Cliffs, 1969, 470p. Englewood Cliffs, 1970, 290p.

13. Encyclopædia of Cybernetics, MULLER, A., ec., Gilbertson, G. transl., Manchester University Press, Manchester, 1969, 214p.

14. OPTNER, S.L. - Systems Analysis for Business Management, Prentice-Hall, Englewood Cliffs, 1968, 277p.

15. OPTNER, S.L. - Systems Analysis for Business an Industrial Problem Solving, Prentice-Hall, Englewood Cliffs, 1965, 116p.

16. ROSOVE, P.E., Developing Computer, Based Information Systems, Wiley, New York, 1967, 384p.

17. RUDWICK, B.H. - Systems Analysis for Effective Planning Principles and Cases. Wiley, New York, 1969, 469p.

18. SHINNERS, S.M. - Tecniques of Systems Engineering. McGrawHill, New York, 1967, 498p.

19. WILLIAMS, W.F. Principles of Automated Information Retrival, Business Press, Elmhurst, 1968, 475p.

20. WILLS, G. and Yearsley, R. es, - Handbook of Management Technology, Funk \& Wagnalls, New York, 1967, 228p.

21. WILSON, I.G. and WILSON, M.E. - Information Computers and Systems, Design. Wiley, New York, 1965, 341p.

22. QUADE, E.S. and Boucher, W.I. eds. Systems Analysis and Policy Planning - Applications in Defense. Elesevier, New York, 1968, 453p.

23. CHESTNUT, H. - Systems Engineering Tools, Wiley, New York, 1966, 646p.

24. HARE, van Court, Jr., Systems Analysis - A diagnostic Approach. Harcout, Brace World, New York, 1967, 544p. 
25. BARNES, M.C. et al. Company Organization - Theory and Practice. Unwin, Chicago, 1970.

26. Information Systems Handbook, Philips Data Systems, Apeldoorn, Netherlands, May, 1968.

27. HOPEMAN, R.J., System Analysis and Operations Management, Merril, Columbus, Ohio, 1969, 346p.

28. SACKMAN, H. Computers, System Science and Evolving Society, Wiley, New York, 1967, 638p.

29. von BERTALANFFY, L. General System Theory - Foundations, Development. Applications. George Braziller, New York, 1969, 289p.

30. BIRKLE, J. and Yearsley, eds., Computer Application in Management, Staples Press, London, 1969, 168p.

31. KLIR, J. and Valach, M. Cybernetic Modelling, ILIFFE, London, $967,437 p$.

32. KLINE, M.B. and LIFSON, M.W. - Systems Engineering. In: J. Morley Engelish. ed. Cost-Effectiveness - The Economic Evaluation of Engineering Systems, Wiley, New York, 1968, 301p.

33. SEILER, K. - Introduction to Systems Cost-Effectivenesse, Wiley, New York, 1969, 108p.

34. WEST CHURCHMAN, C. - The Systems Approach, Delta Book (Dell Public.) New York, 1968, 243p.

35. EMERY, F.E., ed., Systems Thinging, Penguin Books, HarmondsWorth, Middlesex, 1969, 398p.

36. BEER, S., Management Science - The Business Use of Operations Research, Doubleday, Garden City, New York, 1968, 192p.

\section{BIBLIOGRAFIA DE RELATÓRIOS SÔBRE ANALISE E} PROJETO DE SISTEMAS

Sy. SAMUELSON, K. Management Information Systems and Nervous Systems, A comparison of Design Concepts, In: Proceedings of IEEE Systems Science and Cybernetics Conf., Philadelphia, $\mathrm{Pa}$. 1969, 7p. 38. LANCEFORS, B. - Integrated Control by Information System -
Effectiveness and Corporate Goals. IB-ADB 70 n: 23 . Royal Institute of

RM-69. BRETZ, R. Communication Media: Properties and Uses, ....... 6070-NLM/PR. September 1969, Rand Corporation, Santa Monica, 113p.

dards, NSRDS NEWS, vol. 51, n: 1, January 1967, National Bureau of Stanards, Washington.

Engi1. JENKINS, G.M. - The Systems Approach. In: Journal of Systems nineering, vol. 1, Automn 1969, No 1, 3-49p.

SAMUEL SAMUELSON, K., Information Structure and Decision Sequence, In: natio n. North-Holland, Amsterdam, 1968, 622-639p.

Syste 43. GREENE, K.B. - Systems and Psychology, In: de Greene, K.B. ed. Stems Psychology. McGraw-Hill, New York, 1970, 593p. 
